\title{
A paródia em "Conto barroco ou unidade tripartita"
}

\author{
Adolfo José de Souza Frota \\ Mestrando em Letras e Lingüística - UFG. \\ E-mail: adolfo-thedrifter@yahoo.com.br
}

“A paródia é, neste século, um dos modos maiores da construção formal e temática de textos. E, para além disto, tem uma função hermenêutica com implicações simultaneamente culturais e ideológicas"

(Linda Hutcheon)

Mas o mundo é insondável e a obra é insondável. Mundo e obra só nos oferecem algumas de suas faces inumeráveis.

(Osman Lins - Evangelho na taba)

Resumo: O objetivo deste trabalho é analisar o "Conto barroco ou unidade tripartita", de Osman Lins, da coletânea de narrativas Nove novena, no que concerne o seu caráter paródico. Destacaremos a maneira particular como o autor desloca o foco central da história em três partes, as personagens principais, que nos lembram as representações máximas do cristianismo, e, também, como o autor utiliza episódios bíblicos, e dá-lhes a sua interpretação, recontextualizando-os.

Palavras-chave: paródia, desconstrução, hipotexto, hipertexto, ideologia.

Abstract: This paper aims to analyze the short story "Conto barroco ou unidade tripartita", by Osman Lins, from the book Nove Novena, concerning its parodical aspect in this story. We are going to detach the particular way how the author dislocate the central focus of his narrative in three parts, the main characters, that make us remember the Christian Trinity and also how the author takes from the Bible some episodes and gives them his interpretation contextualizing them.

Key-words: parody, deconstruction, hipotext, hypertext, ideology.

O conceito aristotélico de que a arte tinha por princípio a imitação serviu como base para todos os estudos literários desde então. Até hoje, sua teoria ainda é motivo de debates na academia, repercute depois de mais de vinte séculos. Mas, seus estudos de epopéia e de tragédia não conseguem abarcar as outras formas de expressão que surgiram com o decorrer dos anos, como o romance e o conto, por exemplo, não satisfazem os novos anseios de uma sociedade que está sempre mudando, sempre buscando novos parâmetros, e "inventando" novas formas de retratar o mundo, as relações entre os homens. E a literatura, como manifestação do espírito humano, tem servido como mecanismo de difusão ideológica, mas ao mesmo tempo, se volta contra outras. No Dicionário Aurélio, o verbete ideologia aparece como o

[...] conjunto articulado de idéias, valores, opiniões, crenças, etc., que expressam e reforçam as relações que conferem unidade a determinado grupo social (classe, partido político, seita religiosa, etc) seja qual for o grau de consciência que disso tenham seus portadores 
Quando falamos que a literatura serve para a difusão de ideologias, queremos dizer que o autor de uma obra pode estar inserido em uma sociedade e refletir, em sua escrita, os valores de sua época, como, por exemplo, os primeiros românticos brasileiros, que eram nacionalistas por causa dos levantes de independência, e depois de separado da metrópole, queriam autenticar a identidade deste novo país. Para isso, elegeram o índio e natureza como os representantes dessa nova sociedade, e criaram obras sob esses novos parâmetros. Mas a literatura também pode combater alguma ideologia. Estes mesmos românticos combateram a ideologia monárquica e ligada à Portugal, e a invasão portuguesa, como ocorre em Ubirajara, de José de Alencar.

O intuito deste trabalho é observar como a literatura se comporta e reage diante de uma ideologia. Analisaremos o "Conto barroco ou unidade tripartita" de Osman Lins, conto publicado no livro Nove Novena, observando como este autor procede parodicamente ao se referir a Trindade Cristã e à alguns episódios bíblicos, como ele inverte este sistema de valores, da tradição religiosa para uma nova realidade profana; aí se constitui a paródia.

Maria Lúcia de Aragão (1980, p. 18) reconhece que o discurso literário costuma realizar um certo tipo de inversão:

Esta se dá inversamente à efetivada pelo discurso ideológico, pois, se a estrutura ideológica inverte a realidade, e se faz passar por ela, valendose para isso da discursividade, o discurso transformador (o artístico) vai tomá-la em seus efeitos.

Para esta autora, a obra literária é uma inversão dos códigos estabelecidos, (na verdade, acreditamos que a literatura seja uma conjunção) e questiona a ideologia dominante no texto, reconstrói um outro sistema "a partir de uma ruptura com o sistema ideológico vigente, provocando questionamento" (op. cit.,, p. 19). Mas, nem sempre a literatura inverte uma ideologia vigente. Um autor do século XX pode fazer uma paródia contextualizando o seu enredo no século XVII referindo-se a um período anterior.

Para Linda Hutcheon (1985, p. 15) a ruptura nem sempre significa mudança, pois os artistas modernos

[...]

parecem ter reconhecido que a mudança implica continuidade e oferecerem-nos um modelo para o processo de transferência e reorganização desse passado. As suas formas paródicas, cheias de duplicidades, jogam com as tensões criadas pela consciência histórica (grifo nosso).

Isto quer dizer que os parodistas, quando suas obras nos remetem a um passado, valorizam o mesmo, ao invés de criticá-los, diferentemente dos românticos, que apreciavam a originalidade e a individualidade. A paródia serve como um meio de 
entrar em acordo com os textos do passado (op. cit., p. 14-15).

Bella Jozef (1980, p. 53) ao se referir à arte contemporânea, diz que esta costuma assumir uma condição de contestadora da cultura, e "tem elaborado novos modelos de criatividade, alterando os esquemas tradicionais e implicando uma necessidade intrínseca de experimentação". E, continua ela, a paródia "é uma das linguagens da modernidade, que corta a linguagem convencional, invertendo o significado de seus elementos" (op. cit., p. 54). Ao se referir ao modelos, Jozef quis dizer o modelo que origina uma paródia, o texto que serve como parâmetro para a composição.

O "Conto barroco ou unidade tripartita" traz em seu enredo e personagens muitos elementos que justificam se tratar de uma paródia. Também, a sua forma experimental de narração, ajuda-nos a confirmar esta hipótese que trabalharemos a seguir. Para auxiliar a compreensão desse tipo de narrativa como elemento paródico em "Conto barroco..." , falaremos primeiramente da origem da paródia, assim como dos primeiros estudos sobre este tema.

\section{A origem e os primeiros estudos}

Conforme Linda Hutcheon (1985, p. 47, 48), a palavra paródia, em si, já é contraditória. É de origem grega, não se sabendo exatamente quando passou a ser usada. A maioria dos críticos emprega o uso do termo com o sentido de "contracanto". Mas, o prefixo "para" tem dois significados: além de dar a idéia de oposição, e significar "contra", ele também quer dizer "ao longo de", existindo, desta forma, uma sugestão de intimidade, em vez de contraste.

A paródia já era objeto de interesse desde a Poética de Aristóteles (1999, p. 37-40), usada para a análise das epopéias e as apresentações do teatro antigo. 0 poeta grego definiu a poesia como uma representação em versos das ações humanas, opondo-se imediatamente dois tipos de ações, distinguidas por seu nível de dignidade moral e/ ou social: alto e baixo, e os dois modos de representação, narrativa e dramática. As ações altas no modo dramático ocorrem na tragédia e as baixas, ocorrem na comédia. Quanto ao narrativo, Aristóteles não chegou a desenvolvê-lo, ou esta parte não chegou até nós, mas Gérard Genette, em Palimpsestes, (1982, p.17) identifica-a como a paródia. Os textos paródicos, provavelmente, surgiram entre os séculos VII e IV a.C. compostos por Hegemon de Thasos. Na epopéia, por exemplo, a "paródia" ocorria por uma modificação estilística que a transporia de um registro nobre para um mais familiar, até mesmo vulgar, prática esta que se estendeu até o século XVII com as farsas burlescas do tipo Énéide travestie.

$\mathrm{Na}$ Antigüidade clássica, Genette (1982, p. 19) identifica três formas de paródia: a "paródia dramática", da qual Aristóteles não tratou, ou o texto se perdeu com o tempo, tendo como representante a Gigantomaquia; a segunda, uma espécie de "anti-epopéia", que Aristóteles chamou Dilíada (de deilos = frouxo). Esta anti-epopéia seria um oxímoro da llíada, atribuída a Nicochares. As personagens deste segundo tipo 
são reconhecidas pelo filósofo grego como sendo inferiores à média, já que nas epopéias tradicionais, o sujeito representado tinha que ser superior, pois tinha que servir como arquétipo para os ouvintes. E a linguagem também era vulgar. A terceira forma de paródia é a "heróico-cômica", que consiste em representar, no estilo épico (nobre), um sujeito baixo e risível.

Estas três formas de paródia são todas de fato distintas. Para Genette,

[e]lles ont en commun une certaine raillerie de l'épopée (ou éventuellement de tout autre genre noble, ou simplement sérieux, et restriction imposée par la cadre aristolélicien - de mode de représentation narratif) obtenue par une dissociation de as lettre - le texte, le style - et de son esprit: le contenu héroïque (et seq.) ${ }^{[i]}$.

\section{Características da paródia}

A paródia normalmente se refere a uma produção que the é anterior, se relaciona com um outro texto. Genette reconhece isto em Palimpsestes (1982) ao dizer que o texto não é feito por um enunciado só, pois a fonte enunciativa não é singular. Um texto é feito em resposta a outros. Na referida obra, o teórico francês investiga justamente as relações entre os textos, o que ele chama de transtextualidade (transtextualité), definida como "tout ce qui le [texte] met en relation, manifeste ou secréte, avec d'autres textes"[ii]. Partindo deste objetivo, ele identifica "cinq types de relations transtextuelles" (p. 7): a intertextualidade, a paratextualidade, a metatextualidade, a hipertextualidade e a arquitextualidade. Dentre as cinco tipologias, o autor (p. 11-12) investiga a hipertextualidade, que entendida como "toute relation unissant un texte B (que j'appellerai hypertexte) à un texte antérieur A (que j'appellerai, bien sûr, hypotexte) sur lequel il se greffe d'une manière qui n'est pas celle du commentaire" $[$ iiil.

Segundo Yves Reuter (1996, p. 157-158), nesta quantidade variada e enorme de textos de segundo grau, Genette opera muitas distinções segundo a relação, que pode ser de imitação ou de transformação e o regime, que pode ser lúdico, satírico ou sério. As categorias mais conhecidas são de pastiche, que imita o estilo, de paródia e de transposição. Ainda com Yves Reuter que comenta as tipologias genettianas, "a paródia pode utilizar exageros, oposições (entre as personagens ou as ações e o estilo), transposições para um outro espaço-tempo, etc". Porém, não se deve esquecer que esta relação hipertextual pode ser manifesta ou não. Desta forma se explica o fato de que alguns leitores, às vezes, não reconhecem o hipertexto como paródia, quando ignoram a qual hipotexto ela se refere (op. cit., p. 158).

Genette (1982, p. 35), porém, limita a paródia a textos curtos como poemas, provérbios, trocadilhos e títulos. Conforme ele, com algumas ressalvas, "la parodie littéraire s'en prend de préférence à des textes brefs". Ele a entende como a transformação mínima de um texto, e a limita aos modos satíricos e recreativos, admite que a paródia séria possa existir, mas ele não a chama paródia. 
Para Linda Hutcheon (1985, p. 15, 16), que discorda do teórico francês, a paródia é uma relação formal ou estrutural entre dois textos, um modo de chegar ao acordo com os textos do passado, pois esta autora também vê a paródia como uma forma dehomenagear o texto anterior, como acontece com a Eneida, uma "continuação" dos episódios da guerra de Tróia. Mas a paródia não corresponde apenas à imitação ridicularizadora como é descrita nos dicionários. O Ulisses, de James Joyce, é um exemplo patente da paródia do século XX. É um romance sério, segundo a autora. O que antes era um gênero baixo ganha novo status. A proposta de Linda Hutcheon é alargar o conceito de paródia, desmistificando a crença de que ela é apenas u m gênero ligado ao cômico ou ao ridículo. A paródia transforma, mas não precisa ridicularizar o seu alvo. Conforme dissemos há pouco, sua raiz etimológica tem dois significados. O mais tradicional é contra-canto, mas há um segundo sentido para isso. O prefixo "para" também significa "ao longo de", e sugere um acordo e intimidade entre as partes, em vez de um contraste. Hutcheon (op. cit., p. 48) trabalha com a segunda significação, pois esta "alarga o escopo pragmático da paródia de modo útil para as discussões das formas de arte modernas". E nada "existe na paródia que necessite da inclusão de um conceito de ridículo, como existe, por exemplo, na piada ou na burla" (et seq.). Diz a autora que o prazer da ironia da paródia não provém do humor em particular, mas do grau de empenhamento do leitor no "vaivém intertextual", quando o leitor consegue identificá-la com alguma passagem ou evento conhecido. Por vezes, são as convenções tanto como as obras individuais que são parodiadas.

Segundo Bella Jozef (1980, p. 54), a paródia

[...] denuncia e faz falar aquilo que a linguagem normal oculta, pela contradição e relativização que se manifesta no dialogismo essencial do carnaval, através de um discurso descentralizado. O autor introduz uma significação contraditória à palavra da sociedade. Ela só existe dentro de u m sistema que tende à maturidade, pois é uma crítica ao próprio sistema. Através dela cria-se um distanciamento em relação à verdade comum e opera-se a liberdade de uma outra verdade. Na tentativa de descongelar o lugar-comum, a paródia põe em confronto uma multiplicidade de visões, apresentando o processo de produção do texto.

Maria Lucia Aragão (1980, p. 19) diz que o parodiador é, por natureza, um inconformista, que, paradoxalmente, recusa e assume[iv] a própria cultura: “O sentido construtivo de sua obra emerge da destruição dos modelos que então recria". Nesta recusa dos modelos literários, a paródia está denunciando que a estrutura já se esgotou (talvez Aragão se refira à estrutura como se esta fosse o modelo na qual o parodiador se inspira para a sua composição), e que é preciso esvaziá-la para preencher com algo novo. Pois quando um sistema ideológico e literário fica saturado, necessita de um esvaziamento para possibilitar um novo questionamento. O parodista desmistifica todo o sistema sobre o qual os mitos se apóiam, questiona a ideologia, mas não traz respostas, e sim, procura provocar reflexão no leitor.

Diz esta autora que a paródia "mata" para fazer brotar novamente a criação. 
Desconstrói para de novo construir. Dá à tradição novas possibilidades de realização. "A paródia é a conscientização do ultrapassado, no vigente, ou melhor, é o lugar onde se manifesta a dúvida sobre os valores tradicionais" (op. cit., p. 21). Ela chega ao novo, a partir do velho. Dá uma nova leitura para textos e ideologias passadas: atualiza-os.

Já Gérard Genette (1982, p. 20) diz que a “paródia pode ser considerada, de alguma maneira, um tipo de visão especular, em que a imagem original se apresenta invertida, reduzida ou ampliada, de acordo com a lente utilizada". Aragão (1980) reconhece que, nas "obras paródicas, as personagens são geralmente ambíguas e plurivalentes, daí o sentido neste tipo de narrativa nunca ser aquele que nos parece definitivo" (p. 21-22). Ela ganha autonomia, passa a ter vida própria, mas é dependente do primeiro texto para ganhar sentido. É como diz Jozef (1980, p. 65), o texto "que se elabora a partir dos que o precederam, fazendo das relações um processo essencial, presente em toda produção escrita, parcela da intertextualidade, um dos múltiplos entrecruzamentos de textos".

\section{A paródia no "Conto barroco ou unidade tripartita"}

O "Conto barroco..." é uma das melhores narrativas de Nove Novena, obra de grande sucesso editorial e de crítica desde a sua publicação. Este livro inaugura a segunda fase de Osman Lins. É o período intermediário entre as primeiras obras, como Os gestos, $O$ visitante e $A$ rainha dos cárceres da Grécia. Para Ana Luíza Andrade (1987, p. 128), a coletânea está no momento da procura e da plenitude, de transição do autor, "entre um esquema ficcional caracterizado pela busca por parte dos personagens e um plano calculado que possibilita o diálogo entre o texto e o mundo".

o "Conto barroco..." é uma história composta de alternativas tríplices e que se opera no campo do possível. A característica central é o uso da conjunção "ou" tanto no título quanto no decorrer da história. É uma narrativa do tipo comutativa, que pelo uso dessa conjunção, proporciona diferentes alternativas de desenvolvimento do núcleo dramático. Isso significa que nada se realiza. Ninguém chega a um lugar preciso e realiza uma determinada ação. Anatol Rosenfeld (1976, p. 78-86) observa que há uma tendência contemporânea de eliminação do foco central narrativo que transmite a perspectiva (três focos narrativos), pois essas obras tendem a revelar a simultaneidade da vida coletiva das casas ou cidades, e a esses espaços coletivos tendem a eliminar o centro pessoal ou a enfocação sucessiva de uma personagem central.

A história é a seguinte: um matador de aluguel, que é o narrador, está a de José Gervásio não se sabe por qual motivo. Para encontrá-lo, recorre ao auxílio de uma prostituta negra, que teve um caso com Gervásio, oferecendo-lhe dinheiro. Mas esta história, que a princípio parece ser simples e retilínea, ganha três alternativas para o seu desenlace. Em primeiro lugar, o espaço varia entre três cidades: Congonhas, Tiradentes e Ouro Preto, todas cidades barrocas mineiras. Em segundo lugar, a estrutura da narrativa também se desdobra em três alternativas a partir do contato entre o assassino e a negra: em uma delas, o narrador decide partir, pois seu 
envolvimento amoroso atingiu seu ponto fraco, fazendo-o refutar a idéia de cumprir a missão, em outra, a negra apresenta-se com dúvidas se deve ou não entregar José; na última, o assassino se previne contra um possível envolvimento com a prostituta.

A partir deste desdobramento, outro ocorre em seguida para surgir em três novas variações seqüenciais: o narrador recebe a visita do pai de Gervásio, pois este quer se entregar no lugar do filho; ou o perseguido visita seu algoz na tentativa de dissuadi-lo para que não o mate, invocando o seu perdão; ou a negra visita o cliente, que confessa ter contado a José sobre a ameaça de morte por ele sofrida, mas que renova a sua intenção de traí-lo.

Em seguida vem o desfecho da narrativa que, a exemplo dos desdobramentos anteriores, traz três finais possíveis: a negra é morta por engano; o perseguido é morto esfaqueado; o pai dele é assassinado com um tiro. Entre essas narrativas, ocorre outra, que a princípio, são sonhos e alucinações do narrador, em alguns momentos de sua vida.

Osman Lins (1979) já chamava a atenção para esta característica. No Evangelho na taba, ele afirma que "o leitor poderá eventualmente escolher, nesse leque, uma infinidade de contos" (253). O leitor fica, então, convidado para participar da construção da história. Isto é uma das características da poética deste autor, "convidar" o leitor para participar do processo de criação e de significação de suas histórias.

O procedimento paródico em "Conto barroco..." ocorre desde a forma como a história é desenvolvida. Ana Luíza Andrade (1987) diz que ao invés de um trabalho de construção narrativa, o que sobressai "é um trabalho de desconstrução em fragmentos descontínuos" (p. 130), portanto, a paródia se caracteriza tanto pelas personagens, pelas histórias que nos remetem a conhecidas passagens bíblicas, como também pela forma de narração.

Este conto se opõe à cultura eclesiástica, numa forma de carnavalização. Chamamos de carnavalização porque, ao invés de Lins "celebrar" a religião do espírito, ele dá lugar à religião da carne, pois dois das personagens, o assassino e o fugitivo, têm relações sexuais com uma prostituta. Neste enredo há também uma inversão de papéis: as três personagens principais, o matador de aluguel, o foragido e a negra, correspondem a uma paródia da Santíssima Trindade: Pai, Filho e Espírito Santo. Sendo "uma grotesca paródia da tradição cristã" (op. cit., p. 134), o assassino corresponde ao Pai, em seu poder de tirar, e não de dar a vida, o Filho é Gervásio que na verdade se chama Artur, pois este representa Jesus Cristo no interior do país, explorando a crença da população mais pobre, e a negra corresponde ao Espírito Santo, não por unir o Pai ao Filho, mas por trair este último. É o elo entre as duas personagens, como o Espírito Santo é para as duas entidades espirituais, que são, na verdade, uma só. A substituição de sujeito ou ação é para Delepierre (apud GENETTE, 1982, p. 29), uma condição necessária deste gênero: "la 'parodie' modifie le sujet sans modifier le style" (grifo do autor no original).

Outro aspecto que fica bem evidente neste enredo é o uso das imagens 
barrocas, não com o intuito de reforçar a idéia de ser uma história ambientada e escrita nesse estilo epocal, e sim para desconstruir aquela imagem santificada das coisas e dos lugares e, em seguida, para reconstruí-la sob o aspecto humano, pois isto é típico deste procedimento. Diz Genette (1982, p. 56) que "a transformação de um texto produz sempre um outro texto, e, portanto, um outro sentido".

Um exemplo disto ocorre quando o narrador descreve a negra logo após seu encontro amoroso, que se assemelha a uma descrição de um quadro seiscentista, onde notamos o detalhamento profanado de uma imagem barroca:

Nua, no leito, os joelhos redondos para cima, pernas abertas, o braço esquerdo em repouso ao lado dos quadris, a mão direita presa ao gradil recurvo da cama, a colcha de chitão com desenhos de papoulas, palmas entrançadas e grandes magnólias ocultando o sexo e subindo à altura do seu ombro direito, lembra, com o redondo umbigo e os ombros achatados, a atitude de um anjo que vi não me recordo onde, erguendo um cálice (LINS, 1998, p. 122, grifo nosso).

Esta descrição do narrador se aproxima da descrição de um quadro barroco. A paródia se caracteriza porque a descrição acentua as características sexualizadas da "modelo", ressalta a sua feminilidade, diferentemente do que seria a de uma pintura do século XVII. Quando ele se refere à lembrança de um anjo visto não se recorda onde, este detalhe serve como elemento para reforçar a parodização e para aproximar de um quadro seiscentista.

"Conto barroco..." é um texto que contém um outro em si, como ocorre nas paródias, pois percebemos que Lins cria uma história a partir do cristianismo, caracterizando, com isso, uma duplicidade narrativa, pois nele encontramos o "texto" parodiado (a religião cristã) e, ao mesmo tempo, a negação dele (a profanação dos principais elementos da cristandade, como por exemplo, a sexualidade e a morte, opondo-se ao espiritualismo e a vida). O conto está carregado de conotação que pode ser entendida como "a presença do ausente" (JOZEF, 1980, p. 65), pois a paródia pode se caracterizar como a recusa de uma ideologia e de seus valores. Em "Conto barroco..." o cristianismo dá lugar à falta de religião, de valores ligados à tradição do século XVI.

Segundo Jozef (op. cit., p. 54), a paródia também se caracteriza por ser uma escrita de ruptura que procura um corte com os modelos anteriores (neste caso, um conjunto de crenças), invertendo e deslocando-os. Ela retoma a linguagem anterior, mas invertida, revelando a ideologia subjacente, destruindo para construir. Rompe com a tradição e instaura uma nova linguagem. Ao fazer isso, o "autor configura melhor a sua própria linguagem pela diferença ou inversão de significados". No caso de Lins, o que ocorre é um deslocamento de episódios e de personagens, do cristianismo para a falta de parâmetros religiosos, de entidades divinas para seres humanos comuns, com seus defeitos de caráter e contradições.

O pai de Gervásio é uma forma de "reversão bíblica", pois sendo a paródia do pai de Cristo, ele deveria ser Deus. Mas esta personagem é apresentada com dois olhos 
do lado direito e nenhum do lado esquerdo. Acreditamos que Lins quis mostrar que a visão desta personagem é parcial, por isso, limitada, diferentemente, então, do Deus cristão, que tudo sabe e vê. E ele entregou a vida por causa do filho, salvou-o. Em nossa tradição, Cristo é quem resgata a humanidade, em seu ritual de sacrifício. Além de o assassino ser associado à representação divina, a sua atitude como matador de aluguel é bastante controvertida: em um primeiro momento, ele aparece como o profissional frio que mata sem dó suas vítimas. Antes da conversa com o pai de Gervásio, ele diz para si mesmo:

Para bem cumprir meu ofício, não discuto ordens, não as julgo, evito sopesá-las, bem como sopesar ou julgar meus semelhantes, apenas executo-as. Ao executante cabe imunizar-se contra a solerte e até perniciosa intromissão do humano, com sua ética reticente (LINS, 1998, p. 125).

Um pouco adiante, ele afirma: “Tudo tem de ser rápido e neutro, para que o ato a ser cumprido não perca seu caráter impessoal" (p. 134). E na hora que está assassinando o pai de Gervásio, ele reafirma: “Não permitir o mínimo diálogo. Eliminar depressa a vítima. Não consentir-lhe, em nenhuma hipótese, romper a distância que me resguarda de suas artimanhas" (p. 136).

Em outro, ele se mostra reticente, ao perceber que está envolvido emocionalmente com a prostituta:

- Vai embora por quê?

- Você agora existe. Infelizmente.

- Que foi que eu fiz de errado?

- Passou a ser. Não posso explicar. Mas uma puta, uma vítima não podem existir. Se existem, abrem uma chaga no carrasco. Entende isto? (op. cit., p. 124).

Antes da execução, o assassino se pergunta se ele está realmente certo do que deveria fazer. Ainda se mostra em dúvida sobre seu papel na história, mostra-se contraditório:

Ante mim, a menos de dois metros, eu próprio me pergunto: "Estou certo?". Respondo: "Estou?". Antes que nos ocorra a qual de nós compete propor indagações e a qual resolvê-las, escutamos o trote do cavalo, as rodas leves da aranha girando sobre o calçamento, ao mesmo tempo que os sinos das igrejas batem uma pancada e ambos nos afastamos, eu à direita da rua, eu à esquerda, eu hesitante, eu decidido, à espera do condenado (p. 135, grifo nosso).

Mas ao mesmo tempo em que o matador e Gervásio têm papéis definidos dentro da narrativa, eles estão bem próximos um do outro. Os dois exploram a prostituta. Outro ponto que os aproxima é quando o assassino sonha que está se vingando do patrão despótico. José Gervásio é abandonado e traído pelos pais, por isso s e vinga deles comprando um carro e deixando os dois andarem a pé. Quando o 
matador de aluguel conversava com a negra, ela confessou que perdera seu filho ao ser abandonada por Gervásio, e o seu cliente também confessou ter um filho que nunca veria. Foi quando a prostituta reconheceu que eles eram iguais $O$ narrador, em certo momento da história, até se identifica com a sua vítima, ao reconhecer: "esse Gervásio que ao mesmo tempo é ele e eu" (op. cit, p. 123).

Hutcheon (1985, p. 42,43) defende que "a busca da novidade na arte do século XX tem-se baseado com freqüência - ironicamente - na busca de uma tradição". No conto que analisamos, podemos observar isso, quando Lins ambienta as três histórias. Os espaços prováveis do enredo: Ouro Preto, Tiradentes e Congonhas, são três cidades barrocas, nascidas sob uma tradição religiosa. Mas estas três cidades testemunham "a morte de um passado sagrado que é revivido num presente profano" (ANDRADE, 1987, p. 133). Assim, Lins retoma um assunto da tradição cristã com novas cores, substitui um passado bíblico por um presente destituído de qualquer valor religioso.

Ana Luíza de Andrade diz ainda que o conto possui um valor metafórico: a substituição de diferentes realidades. A tríade de personagens (o matador, o explorador e a negra), se plasma na trindade sagrada, e este jogo de metáforas "que nivela duas realidades diferentes já expressa esteticamente uma crítica ética na substituição de Deus como centro do universo - teocentrismo pelo homem, destituído de força espiritual - antropocentrismo" (1987, p. 133).

Alguns episódios em "Conto barroco..." também são paródias de momentos bíblicos. Quando Gervásio tentou dissuadir o assassino para que não o matasse, lembrou de uma peregrinação sua em Sento Sé, no Ceará. Gervásio costumava se fingir de Jesus e peregrinava pelo interior do Brasil com os pais, recordando alguns dos momentos mais marcantes da vida de Cristo. Fazia isso por dinheiro se aproveitando da fé e ignorância dos mais simples. Ele estava na cruz, e naquele dia ganhara muito dinheiro. Diz Gervásio que havia fartura na cidade. E, continua: "Eu gritava da cruz, pedia pelo amor de Deus que não me abandonassem. Meus pais, meus pais, por que vocês me desampararam? Fugiram no jumento e nem olharam para trás (LINS, 1998, p. 129, grifo do autor). O autor de Nove novena recorda, parodicamente, um dos momentos de maior dramaticidade da Bíblia, conhecido pelos cristãos. As citações, paráfrases, e provérbios servem como elementos para o discurso paródico, como ocorre com esse e outros momentos.

Gervásio evoca dois episódios da Bíblia. No primeiro, ele se queixa dos pais que o abandonaram para fugir com o dinheiro que ele tinha ganhado. O segundo lembra a saída de José e Maria do Egito. A diferença é que o casal sagrado fugiu para salvar Jesus, enquanto que os pais de Gervásio o fizeram para ficar com todo o dinheiro. Este Cristo falso e contraditório, à maneira de seu algoz, é capaz de perdoar e, ao mesmo tempo, de se vingar. Quando o assassino pergunta se ele era grato aos velhos, ele responde: “ - Não sou grato. Perdoei-os, como perdôo tudo. Como todos deviam perdoar. E, ao mesmo tempo, me vingo. Vou para toda parte no meu carro, enquanto os dois andam a pé" (LINS, 1998, p. 129). 
A traição da negra lembra a de Judas ao entregar Cristo para os fariseus. A paródia se caracteriza na forma como Jozef (1980) e Genette (1982) a identificam: como uma escrita em dois planos: o plano de parodização, ou seja, o texto enquanto processo de significação, e o plano parodiado, que é o objeto referido pelo primeiro. A paródia só existe por causa de seu hipotexto, só faz sentindo quando conhecemos a sua origem, quando podemos fazer relações e identificações entre o texto que lemos e ao qual ele remete. No momento que o narrador imagina como a negra lhe entregará o perseguido, ele utiliza a famosa frase dita por Judas ao entregar Cristo: “'Este é o homem'" (LINS, 1998, p. 120), logo identificamos se tratar de um episódio bíblico. Por isso, podemos definir esta estratégia como paródia, pois a paródia se justifica quando podemos estabelecer ligações entre os dois textos. Outro exemplo é o conhecido e dramático apelo de Cristo na cruz: "Meus pais, meus pais, por que vocês me desampararam?", aproveitado por Lins por se tratar de um dos episódios mais comoventes da tradição cristã.

Hutcheon (1985, p. 73) defende que um texto paródico seria como uma síntese formal, na incorporação em si mesmo de um texto que the serve de fundo, "mas o duplicar textual da paródia [...] tem por uma função assinalar a diferença". Esta afirmação se enquadra no conto que estamos analisando, pois há uma íntima relação entre as personagens de Lins e as figuras religiosas cristãs, entre as cidades barrocas que testemunham a morte de uma tradição, e, também, entre alguns eventos bíblicos que são parodiados em "Conto barroco...".

Andrade nota que há uma inversão de valores santificados em "Conto barroco...". A morte de Cristo, para a tradição, simbolizava a redenção da humanidade, a nova vida. Já a morte de Gervásio não traz redenção alguma. Nem mesmo se sabe o motivo de seu assassinato, enquanto que conhecemos os motivos que levaram Cristo para a cruz. Ponto mais forte é a inversão que, para a autora, "é completa quando se percebe que para o homem medieval ela era a representação básica da vida, o dogma de fé cristão, que neste conto barroco passa a ter uma função profana e desmoralizadora representando precisamente a morte desta crença" (ANDRADE, 1987, p. 135).

A cruz serviu como uma revelação da santidade de Cristo, pois, ao ser morto, ele ressuscitou. A sua morte se tornou necessária para que resgatasse os pecados da humanidade. O Cristo de Osman Lins fica na cruz em pecado, e sai mais impuro ainda, por enganar a população. É um salvador falso, pois ao abandonar a prostituta negra, ela perde o filho, diferentemente do representante máximo da religião católica, que entregou-se à morte para que os outros tivessem vida.

Lins desconstrói, com esta narrativa, toda uma tradição secular. As personagens assim como o enredo são atualizados por ele. O teocentrismo barroco se converte em antropocentrismo moderno. No lugar de Deus e suas manifestações, têm$s$ ehomens e suas limitações. A entidade que servia como elo (a negra, que corresponde, como dissemos há pouco, o Espírito Santo) entre a representação canônica (Pai e Filho), agora é o agente de separação. Se Deus é aquele que dá vida, a 
referência de Lins é um homem que nem nome tem, e que tem o poder de destruição. Assim observamos que nos três desfechos da história. Lins parodia até a idéia de unidade, pois este número significa a perfeição unitária. O sagrado se torna profano. $\mathrm{E}$ o pai de Gervásio, ao ser morto pelo narrador, ganha um terceiro olho, fruto do disparo de um revólver. Assim, Lins parodia a idéia de que o número três se torna o número do Absoluto. O matador retribui o sacrifício do velho com a oferta simbólica da visão total, pois o terceiro olho na testa, para a cultura indiana, significa a visão totalitária e espiritual. Diz-nos Ana Luíza de Andrade (1987, p. 137) que a personagem principal tem papel fundamental na paródia de Osman Lins:

Na realidade, quando o narrador assassino mata o falso perpetuador do mito da redenção cristã, seu trabalho é um trabalho de desconstrução: destruir o mito da redenção, ainda que falso, é destruir o esquema metafórico da Trindade Santa sobre a qual, fragilmente, está montada a narrativa. Portanto, cada elemento desta tríada, inclusive o substituto de Deus Pai, que é o verdadeiro pai de Gervásio, é eliminado na perfeição desumana do narrador carrasco, sem possibilidade de salvação.

\section{REFERÊNCIAS:}

ANDRADE, Ana Luíza. Osman Lins: crítica e criação. São Paulo: Hucitec, 1987. ARAGÃO, Maria Lúcia P. de. A paródia em "A força do destino". In: Revista do tempo brasileiro. Sobre a paródia. Rio de Janeiro: Edições Tempo Brasileiro LTDA, n. 62, p. 1828, jul. a set. de 1980.

FERREIRA, Aurélio Buarque de Holanda. Dicionário Aurélio. Século XXI. Rio de Janeiro: Nova Fronteira, 1999, p. 1072.

GENETTE, Gérard. Palimpsestes. La literature au second degré. Paris: Seuil, 1982.

HUTCHEON, Linda. Uma teoria da paródia. Ensinamentos das formas de arte do século XX. Tradução de Teresa Louro Pérez. Rio de Janeiro: Edições 70, 1985.

JOZEF, Bella. O espaço da paródia, o problema da intertextualidade e a carnavalização.

In: Revista do tempo brasileiro. Sobre a paródia. Rio de Janeiro: Edições Tempo

Brasileiro LTDA, n. 62, p. 53-70, jul. a set. de 1980.

LINS, Osman. Evangelho na taba. Outros problemas inculturais brasileiros. Org. Julieta Godoy. São Paulo: Summus Editorial, 1979.

. Nove, novena. Narrativas. 4. Ed. São Paulo: Cia das Letras, 1999.

PAES, José Paulo. Palavra feita vida. Posfácio. In: LINS, Osman. Nove, novena. Narrativas. 4. Ed. São Paulo: Cia das Letras, 1999, p. 201-211.

REUTER, YVES. Introdução à análise do romance. Tradução de Ângela Bergamini et all. São Paulo: Martins Fontes, 1996, p. 157-8.

ROSENFELD, Anatol. Texto e contexto. São Paulo: Perspectiva, 1976. 
[i] Elas têm em comum uma certa zombaria da epopéia, (ou eventualmente de outro gênero nobre, ou simplesmente sério e - restrição imposta pelo modelo aristotélico - de modo de representação narrativa) obtida por uma dissociação de sua letra - o texto, o estilo - e de seu espírito: o conteúdo heróico (Todas as traduções serão de nossa autoria)..

¡ii] Tudo aquilo que coloca o texto em relação, manifesta ou secreta, com os outros textos.

[iii] Po r toda relação que une um texto B (que eu chamarei hipertexto) a um texto anterior A (que eu chamarei, claro, hipotexto] sobre o qual ele se enxerta de uma maneira que não é aquela do comentário.

[ivl Na verdade, acreditamos que nem sempre o parodista age dessa forma, pois a paródia pode ser uma reafirmação de determinada cultura, uma homenagem, conforme diz Hutcheon. 